\title{
Forgetting under difficult conditions: Item-method directed forgetting under perceptual processing constraints
}

\author{
Tracy L. Taylor ${ }^{1} \cdot$ Jason Ivanoff ${ }^{2}$ \\ Accepted: 1 February 2021 / Published online: 1 March 2021 \\ (C) The Psychonomic Society, Inc. 2021
}

\begin{abstract}
Intentional forgetting of unwanted items is effortful, yet directed forgetting seems to improve when a secondary task is performed. According to the cognitive load hypothesis of directed forgetting, allocating attentional resources to another task improves forgetting by restricting unwanted encoding of to-be-forgotten (TBF) items. Alternatively, it might be that anything that makes studying more difficult will encourage greater effort to perform the task well and therefore lead to improved intentional forgetting. To assess these proposals we imposed data-processing limitations on study words in an item-method directed forgetting paradigm. Across six experiments, the perceptual quality of study words was manipulated by varying: (1) the duration of study word presentation (Experiments 1-4); (2) the contrast of the displayed word against its visual background (Experiment 5); or (3) the amount of visual background noise on which the word was presented (Experiment 6). In Experiments 4-6, a lexical decision task corroborated the difficulty of study word processing. Despite evidence that relatively low visual contrast and relatively high visual background noise, in particular, create challenging conditions, we found no evidence that perceptual quality impacts the magnitude of the directed forgetting effect. This work suggests that data limitations have no discernible effect on forgetting and corroborate that only attentional resource limitations improve directed forgetting.
\end{abstract}

Keywords Item-method directed forgetting $\cdot$ Intentional forgetting $\cdot$ Data-processing limitations $\cdot$ Cognitive load

\section{Introduction}

In contrast to unintentional forgetting, intentional forgetting at encoding involves the purposeful selection of some items for further processing and the exclusion of other items (see Anderson \& Hanslmayr, 2014, for a review). The paradigm used to elicit this encoding control is referred to as an item-method directed forgetting task and involves presenting participants with study items, one at a time, each followed by an instruction to Remember or Forget (see MacLeod, 1998, for a review). After the presentation of all study items, memory is assessed for both to-beremembered (TBR) and to-be-forgotten (TBF) items. A

Tracy L. Taylor ttaylor2@dal.ca

1 Department of Psychology and Neuroscience, Dalhousie University, Halifax, Canada

2 Department of Psychology, Saint Mary's University, Halifax, Canada directed forgetting effect is defined as better memory for TBR items than TBF items.

Because the study item disappears before the memory instruction is presented (although see Paller, 1990), participants must attend to that item and maintain its representation in working memory (e.g., Gardiner, Gawlik, \& RichardsonKlavehn, 1994; Hsieh, Hung, Tzeng, Lee, \& Cheng, 2009; Paz-Caballero, Menor, \& Jiménez, 2004) until the memory instruction is presented. If the instruction designates the item as TBR, participants engage in elaborative rehearsal (e.g., Hsieh et al., 2009), relying on semantic relational processing (e.g., Montagliani, \& Hockley, 2019) to commit the item to long-term memory. If the instruction designates the item as TBF, participants withdraw attention from the representation of that item (e.g., Taylor, 2005; Taylor \& Fawcett, 2011; Thompson, Hamm, \& Taylor, 2014; Thompson \& Taylor, 2015; see also Lee, 2018), as well as from any other items that occur in close temporal and/or spatial proximity (Fawcett \& Taylor, 2008, 2012; Lee \& Hsu, 2012). This withdrawal of processing resources likely serves to limit - even if not to abolish completely (Lee, Lee, \& Tsai, 2007; see also Bancroft, Hockley, \& Farquhar, 2013) - further unwanted 
rehearsal of the TBF item (e.g., Hourihan \& Taylor, 2006; Jing, Qi, Gao, \& Zhang, 2019). In this way, TBR items receive more rehearsal than TBF items, producing the directed forgetting effect.

Even though selective rehearsal of TBR items is ultimately responsible for the directed forgetting effect (or, at least, primarily responsible: see Marevic \& Rummel, 2020), directed forgetting is fostered by the removal of processing resources from TBF items. This was first demonstrated by Fawcett and Taylor (2008) in a study that embedded visual probe stimuli at varying intervals before and after the memory instructions in an item-method task. Fawcett and Taylor showed that reaction times (RTs) to detect these probes were initially longer when participants were instructed to Forget rather than to Remember. After ruling out alternative explanations, they concluded that trying to intentionally forget is initially more effortful than trying to remember (see also Cheng, Liu, Lee, Hung, \& Tzeng, 2012; Fawcett, Taylor, \& Nadel, 2013a; although see Tan, Ensor, Hockley, Harrison, \& Wilson, 2020), consistent with an initial boost in TBF item processing (Wang, Placek, \& Lewis-Peacock, 2019).

The effort needed to implement an instruction to forget likely reflects the active recruitment of frontal control mechanisms (e.g., Bastin et al., 2012; Rizio \& Dennis, 2013; van Hooff \& Ford, 2011; Wylie, Foxe, \& Taylor, 2008; Xie, Chen, Lin, Hu, \& Zhang, 2020) to withdraw processing resources from the TBF item representation (e.g., see Taylor, 2005; Taylor \& Fawcett, 2011; Thompson et al., 2014; Thompson \& Taylor, 2015). This serves to stop ongoing covert rehearsal of the TBF item (e.g., Hourihan \& Taylor, 2006), in a manner that is similar - even if not identical (Fawcett \& Taylor, 2010) - to the way in which executive control mechanisms are engaged to stop unwanted overt behaviour (e.g., Aron, Fletcher, Bullmore, Sahakian, \& Robbins, 2003; Aron, Robbins, \& Poldrack, 2004; Aron \& Poldrack, 2006). Stopping unwanted TBF item rehearsal is therefore demanding of limited-capacity attentional resources in the short term but ultimately serves to release these attentional resources in the longer term (Popov, Marevic, Rummel, \& Reder, 2019; Taylor, 2018), presumably for further TBR item processing and rehearsal (e.g., Rubinfeld, Taylor, \& Hamm, 2019; Scholz \& Dutke, 2019; Taylor \& Hamm, 2016).

\section{A cognitive load theory of directed forgetting}

A complete failure to recall or recognize TBF items (along with perfect memory for TBR items) may be regarded as ideal performance in a directed forgetting task. In fact, ideal performance for TBF items does not occur, suggesting that some TBF items are encoded (see Bancroft et al., 2013; Hockley, Ahmad, \& Nicholson, 2016; Lee et al., 2007) and can be retrieved (e.g., Marevic \& Rummel, 2020) - despite being represented in a weaker trace (Thompson, Fawcett, \& Taylor, 2011) and with lower fidelity than TBR items (Fawcett, Lawrence, \& Taylor, 2016; see also Ahmad, Tan, \& Hockley, 2019; Fawcett et al., 2013a; Fawcett, Taylor, Nadel, 2013b). Indeed, an instruction to intentionally forget leads to greater recognition than no instruction at all (Gao, Cao, Zhang, Qi, Li, \& Li, 2016; Gao, Qi, \& Zhang, 2019; Zwissler, Schindler, Fischer, Plewnia, \& Kissler, 2015).

Accordingly, Lee (2012; see also Lee \& Lee, 2011; Lee et al., 2007) argued that a cognitively demanding secondary task should consume the limited capacity attentional resources that would otherwise be available to engage in unwanted processing of TBF items (see also Benoni, 2018). The outcome should be less TBF item encoding - and, therefore, enhanced directed forgetting effects - under conditions of high cognitive load rather than low cognitive load. A handful of findings support this idea. When the memory instruction in an item-method task is presented along with a two-digit number that participants must use to initiate counting aloud backwards during a long post-instruction interval, directed forgetting is better when compared to a control task (Lee \& Lee, 2011). Likewise, directed forgetting effects are larger when measured in a task that requires ongoing rehearsal of TBR items than when measured in a naming task where TBR items are read aloud without commitment to memory (Lee, 2012). Finally, participants show larger directed forgetting effects in the context of a relatively long list of TBR items, rather than a relatively short list (Lee, 2012), due presumably to the greater demands that the longer list places on limited-capacity attentional resources during cumulative rehearsal of TBR items. These findings point to enhanced directed forgetting effects in the context of greater load on cognitive control.

In light of these data, Lee and colleagues (Lee, 2012; Lee \& Lee, 2011) proposed a cognitive load hypothesis of directed forgetting, which assumes that directed forgetting may be derailed, ironically, by concentrated efforts to forget (e.g., see Wegner, 1994). Accordingly, an intention to forget is necessary but not sufficient for ideal levels of directed forgetting. Instead, successful directed forgetting further requires that cognitive resources (e.g., attention) be occupied elsewhere (e.g., on another task) to such an extent that they are unavailable for unwanted automatic TBF item processing. Although this cognitive load hypothesis of directed forgetting does not have to account for the full TBR-TBF difference, it does help explain why memory performance for TBF items is often better than zero, with recognition hit rates that exceed the false alarm rate to unstudied foils (e.g., Davis \& Okada, 1971). 


\section{Relating Lee's cognitive load theory to Lavie's load theory}

While Lee's cognitive load account of directed forgetting has enjoyed some success, a key problem with this account of directed forgetting is that it does not quite fit within the broad framework of load theory (e.g., Lavie, 2005, 2010; Lavie, Hirst, de Fockert, \& Viding, 2004). ${ }^{1}$ Load theory was originally proposed as a way to integrate two distinct empirical findings in the literature on distractor interference in attention. First, increasing cognitive load (e.g., working memory challenges) generally increases distractor processing, presumably by disrupting distractor suppression and/or target prioritization. If pigeonholing TBF and TBR items during encoding requires cognitive control akin to maintaining the difference between task-irrelevant and task-relevant information (e.g., Lavie, 2005), or if intentionally forgetting demands more effort than intentionally remembering (e.g., Cheng et al., 2012; Fawcett \& Taylor, 2008; Fawcett et al., 2013a; Gao et al., 2016), then load theory would generally predict more frequent failures to forget (i.e., smaller directed forgetting effects) under conditions that are more resource demanding, not larger directed forgetting effects as posited by Lee's cognitive load hypothesis of directed forgetting.

The second empirical finding that motivated load theory concerns the effects of perceptual load on performance (Lavie, 2010). In distractor tasks, perceptual load can be increased by increasing the number of stimuli in a display or by changing the task (e.g., Murphy, Groeger, \& Greene, 2016). Perceptual load can also be increased by varying the degree to which distractors appear similar to targets (Lavie, 2005): a

\footnotetext{
${ }^{1}$ Lavie's experimental approach to demonstrate the attentional effects of perceptual load has come under scrutiny (e.g., Benoni \& Tsal, 2010; Tsal \& Benoni, 2010; Wilson, Muroi, \& MacLeod, 2011). In a typical perceptual load manipulation (e.g., Lavie \& de Fockert, 2003; Lavie, 2005), a target letter is presented amongst perceptually similar (and varied) neutral distractors. Perceptual load is manipulated by varying the set size of the search array (i.e., greater perceptual load implies more distractor items in the search array). A larger (and quite salient) distractor is presented just next to the search array and is either the same (congruent) or different (incongruent) letter as the target. The congruency difference measures interference. Interference is often smaller as perceptual load increases. Proponents of the dilution account suggest that the reduction of interference from the larger (salient) distractor letter is not due to perceptual load per se, but rather due to the dilution of the interference effect from the salient distractor by the neutral distractors in the search array. Adding to the issue, others (e.g., Gaspelin, Ruthruff, \& Jung, 2014) have argued that some of the effects attributed to load or dilution may be due to the improper allocation of attention to the salient distractor (attentional "slippage"). Load theory, dilution, and "slippage" accounts are laden with processing assumptions that ought not to be disregarded (see, e.g., Cave \& Chen, 2016; Murphy, Groeger, \& Greene, 2016). These methodological considerations are important and ultimately will propel the field toward a better understanding of the fundamental mechanisms of attention. Although this is an important debate, it is outside the scope of the current paper as it is difficult to imagine how some of the nuances explicitly apply to directed forgetting. Accordingly, we will focus on the theoretical aspects of load theory rather than the empirical foundations.
}

high degree of visual similarity makes it difficult to distinguish a target from distractors. Increasing perceptual load decreases distractor processing by engaging full attentional resources on targets. For this reason, in outlining their cognitive load hypothesis of directed forgetting, Lee and Lee (2011) drew comparisons with the known effects of perceptual load stating that "[e]ven though participants did not voluntarily rehearse the [TB]F items after receiving the memory cue, they could not stop processing the $[\mathrm{TB}] \mathrm{F}$ items at the long post-cue interval without simultaneously performing a secondary task. This is analogous to the view that perceptual load determines the selective processing of irrelevant information (e.g., Lavie, 2005)" (p. 625). Lee (2012) made a similar claim, arguing that "[t]he cognitive load hypothesis is also similar to the view that perceptual load determines the selective processing of irrelevant information (Lavie, 2005)" (p. 1119). In other words, Lee's cognitive load hypothesis of directed forgetting argues that increased cognitive load in a directed forgetting task has effects on attentional resources and item/distractor processing that are akin to known effects of increased perceptual load.

\section{Cognitive load or task difficulty?}

Given the uncomfortable fit between Lee's (2012) cognitive load hypothesis of directed forgetting and load theory more broadly, it seems worthwhile to consider an alternative explanation for their (Lee \& Lee, 2011; Lee, 2012) empirical findings: improved forgetting in an item-method directed forgetting task might simply reflect the increased effort needed to process items in a difficult task context. According to this task difficulty hypothesis, focusing on another aspect of the task one that does not necessarily tap into attentional resources - is sufficient to disrupt encoding and rehearsal of TBF items. The more effort put into a task, the more forgetting of TBF items that will take place.

To evaluate the merits of the task difficulty hypothesis versus the cognitive load hypothesis of directed forgetting, it is necessary to dissociate task difficulty from cognitive load. To this end, we draw on a critical distinction, highlighted by Norman and Bobrow (1975), between processing limitations that are determined by the availability of mental resources and those that are determined by the quality of the data input. Resource processing limitations are those that are reached as greater mental resources (e.g., attention) are applied to complex tasks, whereas data limitations are tied directly to the quality of the stimulus. Deploying additional resources (e.g., attention) can occur and is subjectively effortful under both conditions; however, the recruitment of additional resources is expected to improve performance when resources are otherwise limited, but not necessarily when data quality is limited. To understand the latter point, consider the cognitive efforts of an amateur astronomer 
attempting to identify a specific crater (e.g., the Plato crater) on a dimly lit moon that is obscured by clouds. The task of identifying the crater is likely to feel difficult and will prompt concentrated effort. However, this effort matters little because the data are of poor quality and/or because the perceptual system is incapable of overcoming this poor-quality input.

The cognitive load hypothesis of directed forgetting and the alternative task difficulty hypothesis predict the same effects on directed forgetting when task difficulty is defined by resource limitations. However, as summarised in Table 1, these accounts make different predictions when task difficulty is defined by data processing limitations. According to the $\operatorname{cog}$ nitive load hypothesis of directed forgetting, resource limitations should reduce unwanted TBF item processing (improve forgetting) and thereby increase the directed forgetting effect. The corollary is that directed forgetting effects should not be influenced by changes in attention that accompany data-processing limitations. If anything, increased attentional deployment during study item processing would be expected to increase attention to the study item and potentially hinder attempts to intentionally forget. In contrast, according to the task difficulty hypothesis, it does not matter whether the task requires divided attention (i.e., splitting attentional resources) or whether the perceptual processing is made more difficult (i.e., data-processing limitations): it is the increased effort needed to perform the task that naturally leads to greater (or more frequent) withdrawal of attention from TBF items and thus to better forgetting.

\section{Current study}

In Experiments 1-4, we operationalised processing difficulty by varying study word duration: $75 \mathrm{~ms}$ (Difficult), $300 \mathrm{~ms}$ (Moderate), and 1,200 (Easy); in Experiment 5 by varying the relative contrast of the displayed greyscale font against a white background: light grey (Difficult), midrange grey (Moderate), and black (Easy); and, in Experiment 6, by varying the level of background noise upon which a black study word was superimposed: high noise (Difficult), moderate noise (Moderate), and no noise (Easy). In each case, these data limitations were expected to make study word processing more difficult.

\section{Experiment 1: Blocked word durations}

In different blocks of trials, study words were presented for $75 \mathrm{~ms}$ (Difficult), $300 \mathrm{~ms}$ (Moderate), or 1,200 ms (Easy). This manipulation is reminiscent of a study reported by Hockley, Ahmad, and Nicholson (2016) that presented study items for $1,000 \mathrm{~ms}$ or 2,000 ms, followed immediately by an instruction to remember or forget - thereby manipulating the

Table 1 Theoretical accounts of attentional capacity and their predictions as applied to data-limited processing in directed forgetting tasks

\begin{tabular}{ll}
\hline Theoretical account & Presumed mechanisms and their predictions \\
\hline $\begin{array}{l}\text { Lavie's Perceptual and } \\
\text { Cognitive Loads* } \\
\text { (e.g., Lavie \& de Fockert, 2003) }\end{array}$ & $\begin{array}{l}\text { 1. Mechanism: Increasing perceptual load reduces attentional resources available for processing task-irrelevant } \\
\text { items. However, degrading the perceptual features of a task-relevant item (a data-limitation) may lead to greater } \\
\text { allocation of (potentially ineffective) attentional resources to process perceptually weaker task-relevant items. In } \\
\text { most circumstances, without the concurrent recruitment of attentional resources, this will have no impact on the } \\
\text { processing of task-irrelevant processing. }\end{array}$ \\
2. Mechanism: Increasing the load on cognitive control processes impairs the ability to properly allocate attentional \\
resources to task-relevant processing and away from task-irrelevant processing. The implication is that \\
task-irrelevant processes have a greater opportunity to influence performance.
\end{tabular}

Lee's Cognitive Load

(e.g., Lee, 2012)

Task Difficulty
Mechanism: Despite explicit instructions to forget TBF items, some are processed to an extent that they can be retrieved later. Increasing cognitive load in a directed forgetting task is (oddly enough) akin to increasing the perceptual load in an attention task because it removes attentional resources from the task that normally limits unwanted automatic processing of task-irrelevant items.

Prediction (Previously Confirmed): Increasing demands on the cognitive system (an attentional resource limitation) will improve forgetting.

Corollary Prediction (New): Increasing the demands on the perceptual system by degrading stimulus input (a data limitation) during encoding will not improve forgetting. However, it may lead to impaired forgetting if there is a greater allocation of attentional resources during the study phase in an attempt to improve perceptual identification of study items.

Mechanism: Increasing the difficulty of the task (perceptual or otherwise) imposes data limitations and recruits greater attentional resources to process task-relevant information and to filter out task-irrelevant information.

Prediction: Increasing any processing demands, whether it be on the perceptual or cognitive system, will lead to greater effort to perform the task (e.g., to suppress TBF items) and therefore improve forgetting.

*Load theory, as originally posed by Lavie (2005), was intended to account for ways in which task-irrelevant information can be filtered or attenuated in attention tasks. It was never intended to make predictions for the literature on directed forgetting. We have included a consideration of one facet of Lavie's load theory here as it provides the foundation, and the inspiration, for the cognitive load account proposed by Lee (2011). 
time available to process the study item in the pre-instruction interval. Whereas Hockley et al. reported overall poorer recognition at the shorter study item duration than at the longer duration, they reported no interaction with directed forgetting. ${ }^{2}$

On this basis, it might seem probable that our manipulation of study word duration would likewise fail to produce an interaction with directed forgetting. However, even aside from the value of independent replication, further shortening of the study word duration is needed to create conditions that challenge word processing. The shortest duration used by Hockley et al. $(1,000 \mathrm{~ms})$ is nearer our longest duration $(1,200 \mathrm{~ms})$, defined by us as the Easy processing condition because the cascade of neural processing needed to read an isolated word should have more than enough time to be executed in full (e.g., Hauk, Davis, Ford, Pulvermüller, \& Marslen-Wilson, 2006). To the extent that any additional time is therefore used for maintenance rehearsal, Hockley et al.'s (2016) comparison of 1,000-ms and 2,000-ms study word durations was, in effect, a manipulation of maintenance rehearsal duration, rather than a manipulation of processing difficulty. Thus, our goal was to test even shorter word durations than used by Hockley et al. (2016), with the express intention of manipulating the difficulty of initial study word processing per se and not simply the time available to maintain the representation of alreadyprocessed study items.

\section{Method}

\section{Participants}

An initial 36 students from Dalhousie University were recruited in exchange for psychology course credit. One of these participants was replaced with a new recruit after reporting previous experience in a directed forgetting task, contrary to a recruitment criterion. All participants were tested individually in an experimental session that lasted approximately $1 \mathrm{~h}$. The Dalhousie University Social Sciences Research Ethics Board granted ethical approval of this project (i.e., all experiments mentioned herein). All volunteers gave written informed consent prior to data collection.

\section{Stimuli and apparatus}

The experiment was conducted on iMac computers running PsyScope (cf. Cohen, MacWhinney, Flatt, \& Provost, 1993). All text stimuli were presented in black on a uniform white field. A plus sign ("+") served as the fixation stimulus on study trials; a string of seven Rs ("RRRRRRR") served as the

\footnotetext{
${ }^{2}$ A similar finding was reported by Woodward, Bjork, and Jongeward (1973), but is more difficult to interpret because recognition performance was conditionalized on prior recall of each TBR and TBF word.
}

instruction to Remember; a string of seven Fs ("FFFFFFF") served as the instruction to Forget.

A pool of 587 nouns was downloaded from the online MRC Psycholinguistics database (Coltheart, 1981; Wilson, 1988); a total of 288 nouns was selected randomly for use in this experiment. The selected words averaged 4.78 letters $(R=$ $3-7)$ and 1.37 syllables $(R=1-3)$ in length, with an overall concreteness rating of $579.93(R=500-662)$, a familiarity rating of 550.22 ( $R=500-644)$, and Kučera-Francis word frequency rating of $60.45(R=1-1207)$. Prior to collecting data from each participant, custom software was used to first randomise these words and then divide them into six lists of 24 study words each and one list of 144 foil words. The six study lists were assigned to the factorial combination of study word duration (75 ms, $300 \mathrm{~ms}, 1,200 \mathrm{~ms}$ ) and memory instruction (TBR, TBF); the foil list was presented only in the recognition test. This randomization and list assignment was performed anew for every participant.

\section{Procedure}

Participants received both verbal and written instructions telling them that they would be presented with three blocks of study trials followed by a memory test at the very end. They were told that within each block of study trials, words would appear one at a time for a relatively long, medium, or short duration, each followed by an instruction to Remember ("RRRRRRR") or an instruction to Forget ("FFFFFFF"). They were asked to commit the TBR words to memory for a subsequent test but to endeavour to forget the TBF words. Nothing more was said about the memory test except that instructions for this test would follow later in the experiment. Study word duration was blocked and the order was counterbalanced across participants, such that there were six participants run in each of the six $(=3 !)$ possible orders.

Study blocks Each study block started with a written description that indicated the relative duration of the study words. As shown in Fig. 1, at the start of each trial, the fixation stimulus ("+") was presented alone in the centre of the computer monitor for $800 \mathrm{~ms}$ before being replaced by the study word, printed in all lowercase letters. Participants were presented with the word for $75 \mathrm{~ms}, 300 \mathrm{~ms}$, or 1,200 ms, according to the block condition. The computer monitor was cleared and remained blank for 1,000 ms. The memory instruction then appeared in the centre of the computer monitor for $400 \mathrm{~ms}$. After this, the monitor was cleared and remained blank for the remainder of the trial. Total trial duration was fixed at $5,000 \mathrm{~ms}$. In keeping with typical studies of memory, this ensured a constant pace for study item presentation across trials (i.e., one word every $5 \mathrm{~s}$ ). However, it did mean that the post-instruction interval necessarily varied with study 


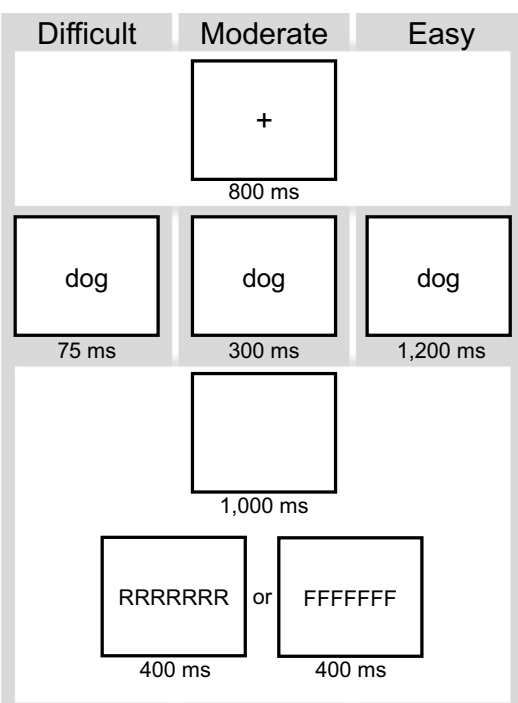

Experiments 1 and 2

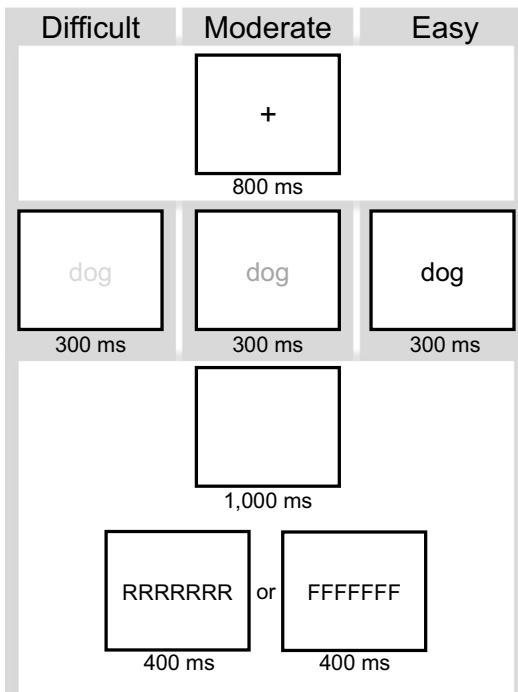

Experiment 5

Fig. 1 Depiction of study trials for Experiments 1 and 2 (top left), Experiment 4 (top right), Experiment 5 (bottom left), and Experiment 6 (bottom right). Experiments 1 and 2 were identical except that word durations were blocked in Experiment 1 and intermixed randomly in a single block in Experiment 2. Experiment 3 (not shown) was identical to Experiment 2 except that all trials were designated to-be-remembered. Experiment 4 replicated the general methods of Experiment 2 except

word duration. We recognised that this issue would need to be addressed (see Experiment 4) but reasoned that the inverse relation between study word processing time and post-instruction processifng time worked in concert to create a strong test of the hypothesis that directed forgetting effects would be largest on the trials with the shortest study word processing times.

Recognition test Following the last trial of the third study block, participants were instructed that they would be presented with test words, one at a time. If they recognised a test word

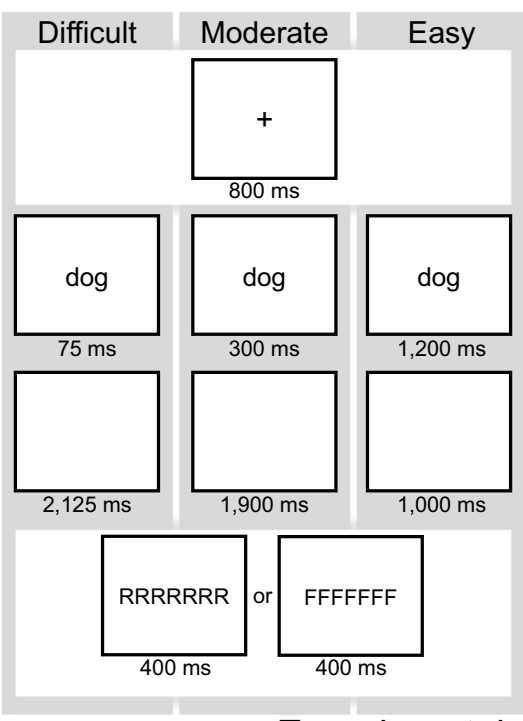

Experiment 4

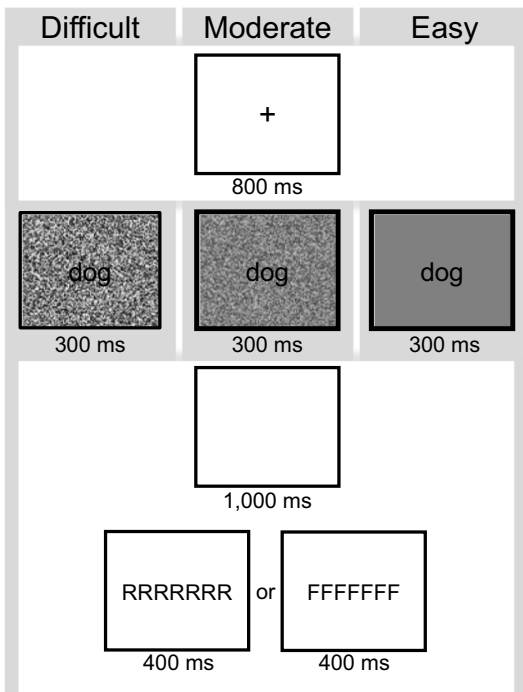

Experiment 6

that the blank interval between the word and the memory instruction was adjusted to accommodate the variable word durations. In Experiments 5 and 6, timings remained constant and what varied was the contrast of the study word against the white background (Experiment 5) or the amount of visual noise on which the black study word was displayed (Experiment 6)

from the earlier study trials, they were to press the "Y" key on the computer keyboard (for "yes"); if not, they were to press the "N" key (for "no"). The instructions emphasised that it did not matter whether a recognised word had been designated TBR or TBF. Keystrokes were echoed to the computer screen; a press of the RETURN key submitted the response and advanced to the next trial. A total of 288 words were tested: the 24 TBR words and $24 \mathrm{TBF}$ words from each of the three different blocks of study trials for a total of 144 study words that were intermixed randomly with 144 unstudied foil words. 
Data analysis Data were collated and analysed using $\mathrm{R}$ Studio 1.1.463 running R 3.5.3 (R Core Team, 2019) and loaded with packages plyr (Wickham, 2011), dplyr (Wickham \& Francois, 2019), tidyr (Wickham \& Henry, 2019), and stringr (Wickham, 2019). We used the R package ez 4.4-0 (Lawrence, 2016) to calculate descriptive statistics (ezStats) and analyses of variance (ezANOVA), and to create plots (ezPlot) that were modified using ggplot2 (Wickham, 2009).

A recognition hit was defined as a "Y" response to a studied TBR or TBF word; a false alarm was defined as a "Y" response to an unstudied foil word. ${ }^{3}$ Before conducting our primary analyses, we calculated the mean false alarm rate across all participants and removed all data contributed by participants whose false alarm rate exceeded this average by more than 2 standard deviations. The remaining data were collapsed into condition means that were analyzed using ezANOVA, the output of which was used to generate a Bayesian Information Criterion (BIC) approximation to Bayesian posterior probabilities using the methods recommended by Masson (2011). This has the advantage of allowing us to compare the weight of evidence that our data provide in support of the null hypothesis versus the alternative hypothesis (see Kruschke \& Liddell, 2017).

Where $p \mathrm{H} 0$ refers to the approximated posterior probability of the null hypothesis given the data and $p \mathrm{H} 1$ refers to the approximated posterior probability of the alternative hypothesis of a non-zero effect, these values sum to 1 . We therefore describe evidence for an effect when $\mathrm{H} 1$ is the larger probability (i.e., $p \mathrm{H} 1>0.50$ ) and evidence against an effect when $\mathrm{H} 0$ is the larger probability (i.e., $p \mathrm{H} 0>0.50$ ). We qualify these effects by applying verbal descriptors as recommended by Raftery (1995), such that probabilities in the range 0.50 0.75 provide "weak" evidence; probabilities in the range 0.75 0.95 provide "positive" evidence; probabilities in the range of $0.95-0.99$ provide "strong" evidence; and, probabilities $>0.99$ provide "very strong" evidence.

\section{Results and discussion}

Data contributed by two participants were removed due to foil false alarm rates that exceeded the mean of all participants by more than 2 standard deviations. Data from the remaining 34 participants are shown in Fig. 2 (top left panel).

\footnotetext{
${ }^{3}$ While false alarm rates are sometimes used in an attempt to correct for guessing by subtracting them from the hit rates, there was a common foil false alarm rate across all levels of the independent variables; this is typical of a directed forgetting task. Because the calculation of a directed forgetting effect across conditions is unchanged by the subtraction of the same false alarm rate from both TBR and TBF item recognition, we have elected to report "uncorrected" hit rates.
}

In the analysis of hit rates to studied items, there was very strong support for an effect of memory instruction, $F(1,33)=$ $136.33, M S e=359.62, p<.01$, ges $=.48, p H 1>.99$. This reflects an overall directed forgetting effect, with more hits to TBR items $(M=66 \%)$ than to TBF items $(M=35 \%)$. As shown in Fig. 2, hit rates did not vary with the difficulty of study word processing. Indeed, there was strong evidence against an overall effect of difficulty, $F(2,66)<1, M S e=136.67, p=.64$, ges $<.01, p \mathrm{H} 0=.98$. Critically, there was also strong evidence against an interaction of memory instruction and difficulty, $F(2,66)=1.30, M S e=$ $63.78, p=.28$, ges $<.01, p \mathrm{H} 0=.95$. The finding of an overall directed forgetting effect, with no effects of processing difficulty, suggests that: (1) at least when presented in a blocked design (see Experiment 2) a representation of TBR and TBF items can be formed even at the shortest presentation duration $(75 \mathrm{~ms})$, with relatively little benefit to later recognition for longer exposure durations; (2) there is no evidence that more difficult datalimited processing influences directed forgetting; and (3) there is no measurable impact of any additional attentional resources that might be recruited to compensate for data-limited input (see also Taylor \& Hamm, in press).

Experiment 1 blocked the presentation of study word duration to encourage participants to adopt different cognitive sets across blocks. We presumed that any adjustments needed to facilitate directed forgetting would most easily be made if participants were aware of the relative difficulty of word processing in the upcoming block of trials. It is possible, however, that the ability to prepare in advance for short study word durations made these durations easier to cope with - effectively undermining the intended manipulation of task difficulty. ${ }^{4}$ To address this possibility, Experiment 2 intermixed the presentation of study word durations.

\section{Experiment 2: Mixed word durations}

Experiment 2 replicated the methods of Experiment 1, except that the three study word durations were mixed together in a single block of trials.

\section{Method}

\section{Participants}

A total of 36 students from Dalhousie University were recruited in exchange for psychology course credit, under the same conditions as described for Experiment 1.

\footnotetext{
${ }^{4}$ This could also account for why the magnitude of the item-method directed forgetting effect does not always vary with overall item memorability in a between-subjects manipulation of stimulus type (e.g., Basden \& Basden, 1996) but does in a mixed-block within-subjects manipulation (Quinlan, Taylor, \& Fawcett, 2010).
} 

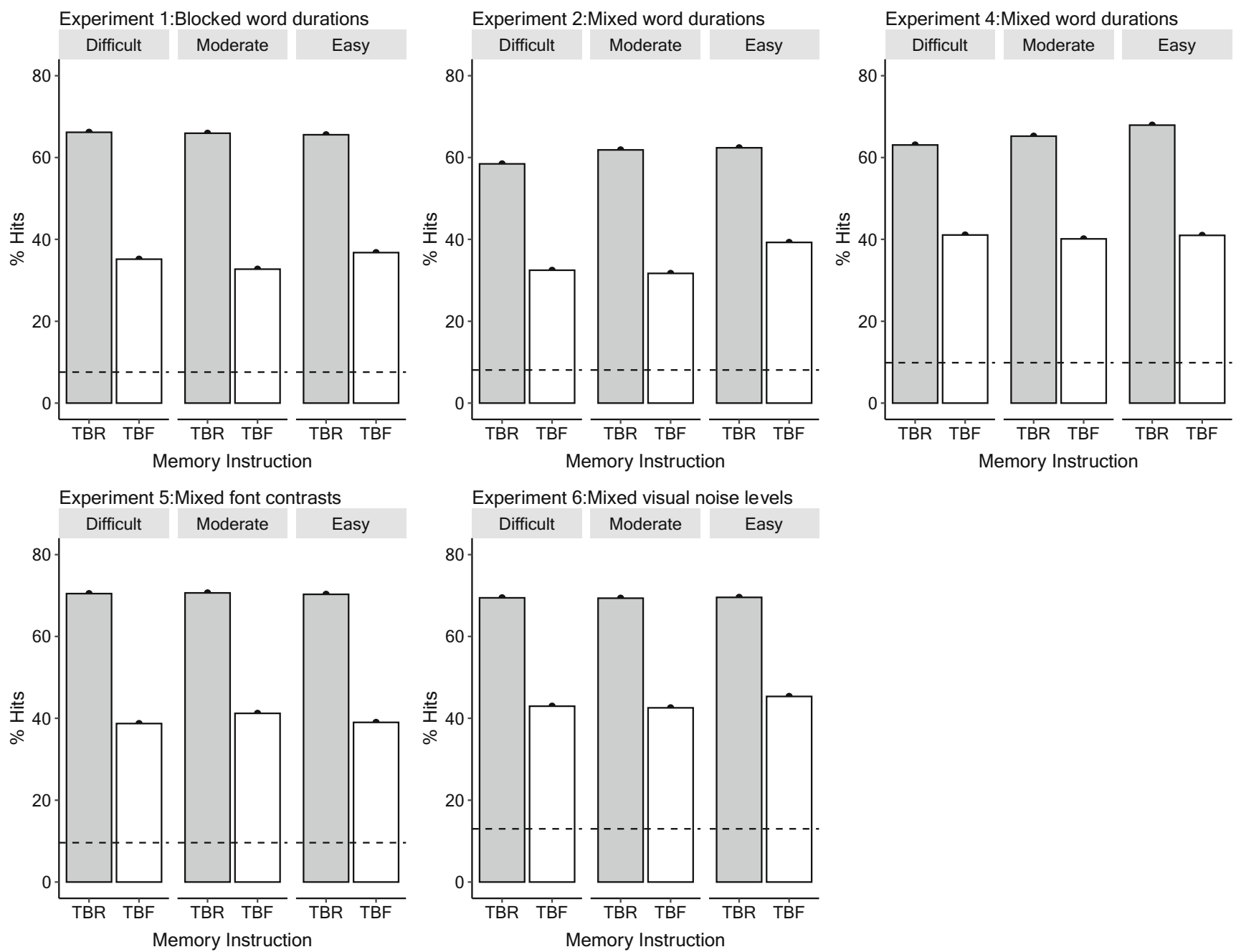

Fig. 2 Mean hits (\%) on the recognition test, for those experiments that presented a directed forgetting task (i.e., excluding Experiment 3). Data are shown as a function of memory instruction (TBR, TBF) and separated by whether study words were presented under Difficult, Moderate, or Easy processing conditions. Task difficulty was manipulated between

\section{Stimuli and apparatus}

The stimuli and apparatus were identical to those used in Experiment 1 .

\section{Procedure}

The procedure was identical to Experiment 1, except that study word durations were intermixed randomly and presented in a single block of study trials.

\section{Results and discussion}

Data from three participants were removed from all subsequent analyses due to mean false alarm rates that exceeded the mean of all participants by more than 2 standard blocks in Experiment 1 but mixed within-blocks for all other experiments. The foil false alarm rates are represented by the dashed horizontal lines $(R$ $=7 \%-13 \%)$ and are plotted on the same scale as used for hits. Error bars depict Fisher's Least Significant Difference for the plotted effect. TBR Tobe-remembered, $T B F$ To-be-forgotten

deviations. Data from the remaining 33 participants are shown in Fig. 2 (top middle panel).

The analysis of hit rates to studied items revealed very strong support for an effect of memory instruction, $F(1,32)$ $=79.16, \mathrm{MSe}=436.83, \mathrm{p}<.01$, ges $=.32, \mathrm{pH} 1>.99$. This reflects an overall directed forgetting effect, with more hits to TBR items $(M=61 \%)$ than to TBF items $(M=34 \%)$. Unlike in Experiment 1, intermixing the study word durations in Experiment 2 provided positive evidence for an overall effect of study word processing difficulty, $F(2,64)=7.29, \mathrm{MSe}=$ $70.69, p<.01$, ges $=.01, p \mathrm{H} 1=0.92$. The overall recognition hit rate was $45 \%$ for words presented under the Difficult ( 75 ms) study condition, $47 \%$ for those presented under the Moderate condition (300 ms), and $51 \%$ for those presented under the Easy (1,200 ms) condition. The fact that overall hit rates improved with increased study word duration is consistent with the supposition that relatively shorter presentation 
times are more challenging than longer ones, at least when all durations are intermixed in a single block of trials. The critical finding, however, is that, like Experiment 1, Experiment 2 provided positive evidence against an interaction of memory instruction and study word processing difficulty, $F(2,64)=$ $2.51, M S e=83.01, p=.09$, ges $=.01, p H 0=.85$. Thus, despite evidence that shorter study word durations were, in fact, more challenging than longer ones (at least for overall recognition), there was no obvious effect on directed forgetting.

Even allowing for the fact that there was no interaction of study word duration with memory instruction, one might question why the effect of study word duration was itself not stronger: there was a 16-fold increase in presentation time between the Difficult (75 ms) and Easy (1,200 ms) conditions that produced only a 1.13 -fold improvement in overall recognition performance $(45 \%$ vs. $51 \%)$. To the extent that longer durations allowed word processing to run to completion and provided time for additional maintenance rehearsal, it is clear that the effects of this rehearsal are characterised by diminishing returns. The fact that this seems to be as true for TBF items as for TBR items indicates not only that the instruction to forget fails to override any strengthening that does occur, but also that an instruction to remember fails to enhance this strengthening. Even though this pattern replicates and extends the results reported by Hockley et al. (2016), it nevertheless seems somewhat surprising that intentionally committing an item to memory does not benefit from a "head start" offered by trace strengthening during maintenance rehearsal. In light of this, we thought it worthwhile to replicate the methods of Experiment 2 using only TBR trials. This allowed us to determine whether - in a more typical memory task ("remember everything") - there would be a more pronounced effect of study word duration on the intentional commitment of words to memory.

\section{Experiment 3: Mixed word durations, remember all}

The methods of Experiment 3 were identical to those of Experiment 2, except that every trial presented an instruction to Remember.

\section{Method}

\section{Participants}

A total of 36 students from Dalhousie University were recruited in exchange for psychology course credit, under the same conditions as described for Experiment 1.

\section{Stimuli and apparatus}

The stimuli and apparatus were identical to those used in Experiment 2, except that all trials presented a Remember instruction. Thus, the 144 study words were distributed over the three levels of study word duration $(75 \mathrm{~ms}, 300 \mathrm{~ms}$, and $1,200 \mathrm{~ms})$.

\section{Procedure}

The procedure was identical to Experiment 1, except that a Remember instruction was presented on every trial. Participants were aware that all study words would be designated TBR.

\section{Results and discussion}

Data from one participant were removed from all subsequent analyses due to a mean false alarm rate that exceeded the mean of all participants by more than 2 standard deviations. Analyses were conducted on data contributed by the remaining 35 participants.

The analysis of hit rates to studied items revealed only weak support for an effect of task difficulty, $F(2,68)=5.29$, $M S e=32.81, p=.01$, ges $=.01, p H 1=.68$. Importantly, this did not suggest better encoding of words presented for longer durations: the hit rates were nearly identical for words presented at the shortest (i.e., $75 \mathrm{~ms} ; M=63 \%$ ) and longest (i.e., $1,200 \mathrm{~ms} ; M=62 \%$ ) durations, with a small - and likely not robust - dip in performance at the intermediate duration (i.e., $300 \mathrm{~ms} ; M=59 \%$ ).

The fact that TBR item hit rates were near-identical at the shortest and longest study word durations accords with our suggestion that the difference in these presentation durations was not enough to prompt meaningful changes in intentional remembering. When TBR items are studied in the context of TBF items, their subsequent recall is improved relative to when TBR items are studied on their own (e.g., Sahakyan \& Foster, 2009) - a benefit attributable to retrieval processes (Lee, 2013). It is not clear, however, that such benefits hold when memory for TBR items is tested using recognition (see Taylor, Quinlan, \& Vullings, 2018, for a discussion of this issue with respect to recognition of pictures). To the extent that recognition performance for TBR items in Experiment 3 can therefore also speak to recognition performance for TBR items in Experiments 1 and 2, it follows that the failure to reveal an interaction of directed forgetting with task difficulty in those experiments was likely not due to changes in TBR item recognition that otherwise mask changes in TBF item recognition (i.e., considering that directed forgetting is measured as a difference score). Ignoring, temporarily, that this situation is predicted by the cognitive load account (as with the amateur astronomer, increased attention may not improve 
performance under conditions of data-limited processing), the fact that there was no discernible effect of item duration on directed forgetting in Experiments 1 and 2, with no effects on TBR item recognition in Experiment 3, raises the spectre that this manipulation did not, in fact, sufficiently challenge study word processing. The fact that the overall hit rate in Experiment 2 was affected by study word duration hints at the effectiveness of this manipulation. However, the goal of Experiment 4 was to provide independent corroboration.

\section{Experiment 4: Mixed word durations, lexical decision, changed delays}

Experiment 4 replicated Experiment 2, with the following two changes. First, we presented a lexical decision task prior to conducting the study trials. In the lexical decision task, participants were required to indicate as quickly as possible whether a letter string was arranged to form a word (word) or non-word (wrod). This letter string was presented for $75 \mathrm{~ms}$ (Difficult), $300 \mathrm{~ms}$ (Moderate), or 1,200 ms (Easy). The expectation was that lexical decision RTs would be longer with shorter presentation durations, thereby confirming that shorter word durations create more difficult processing conditions.

Second, we varied the duration of the blank interval that followed each study item on Difficult, Moderate, and Easy trials. This allowed us to maintain a constant presentation rate (i.e., one study item every $5 \mathrm{~s}$ ) while equating post-instruction processing time. Had there been an interaction of memory instruction and difficulty in Experiments 1 and/or 2, it would have been critical to determine whether this was due to study word duration and/or post-instruction interval. The need to separate these effects is not so obvious in the absence of such an interaction. Nevertheless, Experiment 4 provided an opportunity to equate post-instruction processing time and thereby further evaluate any potential effects of study word duration on directed forgetting.

\section{Method}

\section{Participants}

To accommodate the addition of a lexical decision task, we increased our targeted recruitment to 48 participants; we did not review or analyse the data prior to completing this recruitment. Participants were recruited under the same conditions as described for Experiment 1.

\section{Stimuli and apparatus}

The stimuli and apparatus were as described for Experiment 2, except that a lexical decision task presented participants with a letter string configured as a word or non-word. The letter string on word trials was always word and on non-word trials was always wrod. This was to ensure that stimuli presented in the lexical decision task did not interfere with subsequent recognition memory performance.

\section{Procedure}

Lexical decision task Each lexical decision trial started with an 800-ms presentation of a fixation stimulus ("+") in the centre of the computer monitor, followed by the letter string word or wrod, which remained visible for $75 \mathrm{~ms}$ (Difficult), $300 \mathrm{~ms}$ (Moderate), or 1,200 ms (Easy). Participants were instructed to respond as quickly and as accurately as possible by pressing the "W" key for "word" or the "N" key for "non-word". A total of ten trials were presented at each level of the factorial crossing of difficulty $(75 \mathrm{~ms}, 300 \mathrm{~ms}$, and $1,200 \mathrm{~ms})$ and lexical status (word, non-word), for a total of 60 lexical decision trials. The total duration of each trial was $3,500 \mathrm{~ms}$.

Study trials The study trials were identical to Experiment 2 except, as depicted in Fig. 1 (top right panel), when the study word was presented for only $75 \mathrm{~ms}$, the memory instruction appeared after a delay of $2,125 \mathrm{~ms}$; when the study word was presented for $300 \mathrm{~ms}$, the memory instruction appeared after a delay of 1,900 ms; and when the study word was presented for $1,200 \mathrm{~ms}$, the memory instruction appeared after a delay of $1,000 \mathrm{~ms}$.

Recognition test The recognition test was identical to that of Experiment 2.

\section{Results and discussion}

For the lexical decision task, individual trials were set to be excluded if no response was made before the end of the trial; if a key other than a "W" or "N" was pressed; and if the RT for a given trial was more than 2 standard deviations faster or slower than the mean of all trials across all participants. No trials were identified as meeting these exclusion criteria. Responses were then coded as correct or incorrect and the mean lexical decision accuracy was calculated for each participant, without regard for stimulus duration (i.e., task difficulty). Two participants were identified as having a mean lexical decision accuracy that was more than 2 standard deviations below the mean of all participants. While still including the data from these participants, an additional three participants were identified as having foil false alarm rates that exceeded the mean of all participants by more than 2 standard deviations. Based on these preliminary findings, the data from a total of five participants were removed from all subsequent analyses. The following reports the results for the remaining 43 participants. 
Table 2 Reaction times (RTs) and accuracy (\% correct) for lexical decisions made under Difficult, Moderate, and Easy processing conditions in Experiments 4, 5, and 6. Difficulty was defined by word duration in Experiment 4, font contrast in Experiment 5, and visual noise background in Experiment 6

\begin{tabular}{|c|c|c|c|c|}
\hline Experiment & Measure & Difficult & Moderate & Easy \\
\hline \multirow[t]{2}{*}{ Experiment 4: Mixed word durations } & RT & $556(9.96)$ & $569(8.92)$ & $569(9.44)$ \\
\hline & Accuracy & $91(1.27)$ & $96(0.71)$ & $94(1.12)$ \\
\hline \multirow[t]{2}{*}{ Experiment 5: Mixed font contrasts } & RT & $571(7.15)$ & $542(7.15)$ & $541(6.80)$ \\
\hline & Accuracy & $91(1.16)$ & $94(0.94)$ & $94(0.79)$ \\
\hline \multirow[t]{2}{*}{ Experiment 6: Mixed visual noise levels } & RT & $640(13.05)$ & $623(13.66)$ & $600(12.87)$ \\
\hline & Accuracy & $94(0.93)$ & $93(1.24)$ & $93(1.27)$ \\
\hline
\end{tabular}

Numbers in parentheses are the standard error of the mean

Lexical decision task The results of the lexical decision task are summarised in Table 2. An analysis of the lexical decision RTs provided positive evidence for an overall effect of difficulty, $F(2,84)=6.23, M S e=374.08, p<.01$, ges $=.01, p \mathrm{H} 1=$ .81 . However, the pattern was opposite the prediction that lexical decision RTs would be fastest when the task was easy: pairwise comparisons provided positive evidence for faster RTs in the Difficult condition compared to the Moderate condition, $F(1,42)=8.77, M S e=403.51, p=.01$, ges $=.01, p \mathrm{H} 1=$ .90 , but positive evidence against a difference between the Moderate and Easy conditions, $F(1,42)<1, M S e=290.06$, $p=.96$, ges $<.01, p \mathrm{H} 0=.87$.

The pattern of lexical decision RTs is rather surprising, given that short word durations were expected to make item processing more difficult than longer word durations. It seems possible that participants tended to match response time with word duration. Such a strategy would speed response time at the shortest durations, but at the cost of accuracy. Indeed, in the analysis of lexical decision accuracies, there was positive evidence for an overall effect of difficulty, $F(2,84)=7.16$, $M S e=34.35, p<.01$, ges $=.08, p \mathrm{H} 1=.90$, with pairwise comparisons providing strong evidence for lower accuracies in the Difficult condition $(M=91 \%)$ compared to the Moderate condition $(M=96 \%), F(1,42)=14.74, M S e=$ $33.31, p<.01$, ges $=.11, p \mathrm{H} 1=0.99$, with weak evidence for a difference in accuracy between the Moderate and Easy $(M=94 \%)$ conditions, $F(1,42)=4.01, M S e=26.29, p=.05$, ges $=.03, p \mathrm{H} 1=.52$. In other words, lexical decisions for the shortest presentation duration $(75 \mathrm{~ms})$ tended to be faster but also less accurate than for the longer stimulus presentation durations. This result does point to a strategic shift wherein participants were willing to accept weaker evidence for their responses in the Difficult condition compared to the Moderate and Easy conditions.

Recognition task Recognition hit rates are shown in Fig. 2 (top right panel) as a function of memory instruction (TBR, TBF) and task difficulty (Difficult, Moderate, Easy). An analysis of these data revealed very strong support for an effect of memory instruction, $F(1,42)=128.82, \mathrm{MSe}=304.90, p<.01$, ges $=.34, p \mathrm{H} 1>.99$. This reflects an overall directed forgetting effect, with more hits to TBR items $(M=65 \%)$ than to TBF items $(M=41 \%)$. There was positive evidence against an effect of task difficulty, $F(2,84)=1.66, M S e=79.54, p=$ .20 , ges $<.01, p \mathrm{H} 0=.94$, with no discernible effect of study word duration on overall hit rates. And there was strong evidence against the critical interaction of memory instruction and task difficulty, $F(2,84)=1.51, M S e=88.99, p=.23$, ges $<.01, p \mathrm{H} 0=.95$.

Taken together, the results of Experiments 1, 2, and 4 demonstrate that study item duration has no discernible effect on directed forgetting. The results of Experiment 3 further demonstrate that study item duration has no discernible effect on intentional remembering. These findings provide early support for the cognitive load hypothesis and do not match the predictions of the task difficulty hypothesis. That said, however, all four experiments manipulated task difficulty in the same way (i.e., by varying study word presentation time). We therefore thought it worthwhile to test the generality of this conclusion by varying how study word processing difficulty is operationalised. In two final experiments, we presented study words for a constant duration but manipulated data processing difficulty by varying the visual contrast of study words relative to their background (Experiment 5) or by superimposing those words on backgrounds of varying levels of visual noise (Experiment 6).

\section{Experiment 5: Mixed font contrasts}

In Experiment 5, we varied the visual contrast of the study words against the uniform white background on which they were presented. There were three levels of contrast: words were presented in a light grey font only 
a few shades darker than the white background; in a medium grey font; or in a high contrast black font. The rationale was that study words would be relatively more difficult to read the lower the contrast of those words against their white background. A lexical decision task preceded the study trials. The expectation was that RTs to make a word/non-word discrimination would be longer the more difficult it was to discern the letter string against its background (i.e, the lower the visual contrast).

\section{Method}

\section{Participants}

A total of 48 students from Dalhousie University earned course credit in exchange for their participation, under the same conditions described for Experiment 1.

\section{Stimuli and apparatus}

The stimuli and apparatus were as described for Experiment 4, except for the following. SuperLab 5.0.5 (Cedrus) was used to control stimulus presentation and data collection. Contrast was manipulated by varying the brightness of the greyscale font used to present lexical decision stimuli and study words: 92\% brightness appeared as a light grey against the white background and was therefore of low visual contrast (Difficult); $46 \%$ brightness appeared as a mid-range grey of moderate visual contrast (Moderate); and 0\% brightness appeared as a high contrast black (Easy).

\section{Procedure}

Lexical decision task The lexical decision task was as described for Experiment 4, except that all stimuli were presented for $300 \mathrm{~ms}$ in a light grey, mid-range grey, or black font.

Study trials Study trials were as described for Experiment 2 except that visual contrast was varied instead of word duration. As depicted in Fig. 1 (bottom left panel), trial timings were selected to correspond with the Moderate study word duration of Experiments 1-3 such that the fixation stimulus appeared for $800 \mathrm{~ms}$, followed by the study word for $300 \mathrm{~ms}$, a blank interval for $1,000 \mathrm{~ms}$, and a memory instruction for 400 $\mathrm{ms}$. The total trial duration was $5,000 \mathrm{~ms}$.

Recognition test The recognition test was as described for Experiment 1.

\section{Results and discussion}

Fewer than $3 \%$ of all lexical decision trials were removed due to exclusions. One participant was identified as having a mean lexical decision accuracy that was more than 2 standard deviations below the mean of all participants. While still including the data from this participant, an additional three participants were identified as having foil false alarm rates that exceeded the mean of all participants by more than 2 standard deviations. The data from these four participants were removed from all subsequent analyses. The following reports the results for the remaining 44 participants.

Lexical decision task The results of the lexical decision task are summarised in Table 2. An analysis of the RT data provided very strong evidence for an effect of difficulty, $F(2,86)$ $=40.48, M S e=327.59, p<.01$, ges $=.09, p \mathrm{H} 1>.99$. Indeed, there was very strong evidence for RTs to be longer in the Difficult condition $(M=571 \mathrm{~ms})$ than in the Moderate condition $(M=542 \mathrm{~ms}), F(1,43)=57.79, M S e=336.63, p<.01$, ges $=0.09, p \mathrm{H} 1>.99$. There was, however, positive evidence against a difference in the speed to respond to items presented in the Moderate condition compared to the Easy condition $(M$ $=541 \mathrm{~ms}), F(1,43)<1, M S e=254.56, p=.85$, ges $<.01, p \mathrm{H} 0=$ .87 . The analysis of lexical decision accuracy provided weak evidence against an effect of difficulty, $F(2,86)=4.33, M S e=$ $25.18, p=.02$, ges $=.04, p \mathrm{H} 0=.57$, with the lowest accuracy in the Difficult condition that also produced the longest RTs (i.e., when items were presented in a light grey font on white).

The results of the lexical decision task suggest that the items printed in the mid-range grey and black were equally difficult to process. Functionally, this means that the use of three different contrast levels did not produce three distinct levels of difficulty as intended. Nevertheless, there was still evidence that items presented in the light grey colour were particularly challenging to process. With this in mind, the question was whether the challenge created by this condition would interact with the directed forgetting effect.

Recognition task Recognition hit rates are shown in Fig. 2 (bottom left panel) as a function of memory instruction (TBR, TBF) and difficulty (Difficult, Moderate, Easy). An analysis of these data revealed very strong support for an effect of memory instruction, $F(1,43)=239.60, M S e=$ $261.83, p<.01$, ges $=.47, p \mathrm{H} 1>.99$. This reflects an overall directed forgetting effect, with more hits to TBR items ( $M=$ $70 \%)$ than to TBF items $(M=40 \%)$. There was strong evidence against an effect of task difficulty, $F(2,86)<1, M S e=$ $81.23, p=.54$, ges $<.01, p \mathrm{H} 0=.98$, with near-identical overall hit rates across the three levels of difficulty. On the critical interaction, there was strong evidence against an interaction of memory instruction and task difficulty, $F(2,86)<1, M S e=$ $90.55, p=.69$, ges $<.01, p \mathrm{H} 0=.98$. 
Experiment 5 was designed to investigate the effect of study word processing difficulty by manipulating visual contrast, with the goal of further examining the potential effect of processing difficulty on directed forgetting. The lexical decision RTs confirmed that the most Difficult task condition (low contrast light grey items presented on a white background) was, indeed, more challenging than the Moderate (mid-grey) and Easy (black) conditions. But there was no evidence in the analysis of recognition hit rates that this challenge influenced the magnitude of the directed forgetting effect, again supporting the predictions of the cognitive load hypothesis and failing to provide evidence in favour of the task difficulty hypothesis.

\section{Experiment 6: Mixed visual noise levels}

In Experiment 6, study word processing difficulty was again manipulated. Study words were presented in black for the same fixed duration across trials, superimposed on background images of high, moderate, or no visual noise. This manipulation presumes that higher levels of visual noise increase the relative difficulty of discerning the study word. A lexical decision task preceded the study trials.

\section{Method}

\section{Participants}

A total of 48 Dalhousie University students earned course credit in exchange for their participation and were run under the same conditions as described for Experiment 1.

\section{Stimuli and apparatus}

The stimuli and apparatus were identical to Experiment 5, with two exceptions. All lexical decision and study items were presented in black font and centred in an image of high, moderate, or no visual noise. These background images filled the entire area of the computer monitor. They were mean-centred on a grey-scale value mid-point between white $(0)$ and black (1), such that they were equiluminant with one another. The high noise (Difficult) image consisted of a distribution of values randomly sampled from a $100 \%$ range around midpoint (i.e., $R=0-1, M=0.50$ ); the moderate noise image (Moderate) consisted of a distribution of values randomly sampled from a $50 \%$ range centred on the mid-point (i.e., $R$ $=0.25-0.75, M=0.50$ ); and the no-noise image (Easy) consisted of a $0 \%$ range centred on the mid-point (i.e., $M=$ $0.50)$, to make a uniform grey.

\section{Procedure}

The procedure was identical to Experiment 5.

\section{Results and discussion}

Fewer than $3 \%$ of all lexical decision trials were removed due to exclusions. Two participants were identified as having mean lexical decision accuracies that were more than 2 standard deviations below the mean of all participants. While still including these datasets, an additional four participants were identified as having foil false alarm rates that exceeded the mean of all participants by more than 2 standard deviations. The data from these six participants were removed from all subsequent analyses. The following reports the results for the remaining 42 participants.

Lexical decision task The mean lexical decision RTs and accuracies are shown in Table 2. An analysis of the RT data provided very strong evidence for an effect of difficulty, $F(2,82)=34.52, \mathrm{MSe}=504.09, p<.01$, ges $=.04, p \mathrm{H} 1>$ .99. Indeed, there was strong evidence for RTs to be longer in the Difficult condition than in the Moderate condition, $F(1,41)$ $=12.17, \mathrm{MSe}=518.70, p<.01, \mathrm{ges}=0.01, p \mathrm{H} 1=0.97$, and very strong evidence for RTs to be longer in the Moderate condition than in the Easy condition, $F(1,41)=21.90, M S e$ $=517.19, p<.01$, ges $=.02, p \mathrm{H} 1>.99$. An analogous analysis of the lexical decision accuracy revealed strong evidence against an effect of task difficulty, $F(2,82)<1, M S e=32.74$, $p=.79$, ges $<.01, p \mathrm{H} 0=.98$.

The fact that the lexical decision RTs increased with task difficulty is consistent with the supposition that higher levels of visual noise challenged the perceptual processing of the superimposed visual stimulus. Happily, the lexical decision RTs distinguished among all three levels of purported task difficulty - RTs were slowest in the Difficult high noise condition, intermediate in the Moderate noise condition, and fastest in the Easy no noise condition. With this in mind, the key question was whether increased processing difficulty would interact with the directed forgetting effect.

Recognition task Recognition hit rates are shown in Fig. 2 (bottom right panel). An analysis of these data revealed very strong support for an effect of memory instruction, $F(1,41)=$ 191.70, $\mathrm{MSe}=219.21, p<.01$, ges $=.39, p \mathrm{H} 1>.99$. This reflects an overall directed forgetting effect, with more hits to TBR items $(M=69 \%)$ than to TBF items $(M=44 \%)$. There was strong evidence against an effect of difficulty, $F(2,82)<1$, $M S e=108.79, p=.61$, ges $<.01, p \mathrm{H} 0=.98$, with no discernible difference in overall recognition hit rates for words presented in the Difficult, Moderate, and Easy conditions. In addition, there was strong evidence against an interaction of memory instruction and difficulty, $F(2,82)<1, M S e=105.12$, 
$p=.67$, ges $<.01, p \mathrm{H} 1=.98 .^{5}$ Thus, there was again no evidence that difficult study word processing affected the magnitude of the directed forgetting effect.

\section{General discussion}

There is improved forgetting (i.e., less recognition of TBF items) when participants begin counting backwards at the same time as the memory instruction is presented (Lee \& Lee, 2011); when they must provide ongoing rehearsal to TBR items rather than merely reading these items aloud (Lee, 2012); and when they are required to rehearse a

\footnotetext{
${ }^{5}$ Prior to conducting Experiment 6, two undergraduate projects used similar methods but with different numbers of backgrounds and/or study trial timings. A project conducted by Noha Mohamed used only two levels of background noise, both of which had the appearance of a patterned background: A highnoise background was sampled from a $96 \%$ range around midpoint $(R=0.02$ $0.98, M=0.50$ ) and a low-noise background was sampled from an $8 \%$ range centred on the mid-point $(R=0.46-0.54, M=0.50)$. A total of 160 study trials presented the fixation stimulus for $1,000 \mathrm{~ms}$; the study word superimposed on noise background for $500 \mathrm{~ms}$; a blank interval for $800 \mathrm{~ms}$; the TBR or TBF instruction for $500 \mathrm{~ms}$; and a blank interval for $700 \mathrm{~ms}$, for a total trial duration of 3,500 ms. There were a total of 320 recognition trials comprised of the 160 study words and 160 unstudied foil words. The initial sample size was 34 participants. One datafile was corrupt and could not be analyzed and one dataset was excluded due to a high false alarm rate. Recognition hit rates for the remaining 32 participants showed very strong evidence for an effect of memory instruction, consistent with a directed forgetting effect, $F(1,31)=$ $102.60, M S e=119.33, p<.01$, ges $=.27, p \mathrm{H1}>.99$; weak evidence against an effect of task difficulty, $F(1,31)=3.27, M S e=60.98, p=.08$, ges $<.01$, $p \mathrm{H} 0=.53$; and positive evidence against an interaction of memory instruction and task difficulty, $F<1, M S e=28.84, p=.46$, ges $<.01, p \mathrm{H} 0=.81$. With the high-noise and low-noise backgrounds, respectively, the TBR item hit rate was $59 \%$ and $60 \%$ and the TBF hit rate was $38 \%$ and $41 \%$.

The second undergraduate project conducted by Jessie Pappin used the same methods described for Experiment 6 except that the memory instruction was presented for $300 \mathrm{~ms}$ (instead of $400 \mathrm{~ms}$ ); total trial duration was $5,700 \mathrm{~ms}$ (instead of 5,000 ms); and, there were 33 lexical decision trials (instead of 60), 162 study trials (instead of 144), and 324 test trials (instead of 288). She collected data from 48 participants. Data from two participants were removed due to low lexical decision accuracies and data from another three were removed due to high false alarm rates. The results were very similar to those of Experiment 6 . The lexical decision RTs provided strong evidence for task difficulty, $F(2,84)=8.86, M S e=1209.75, p<.01$, ges $=.02, p \mathrm{H} 1=.98$, with positive evidence for slower RTs in the Difficult condition $(M=636 \mathrm{~ms})$ compared to the Moderate condition $(M=619 \mathrm{~ms}), F(1,42)=9.09, M S e=$ $651.47, p<.01$, ges $=.01, p \mathrm{H1}=.91$, but weak evidence against a difference in the speed of responding in the Moderate condition compared to the Easy ( $M$ $=604 \mathrm{~ms}$ ) condition, $F(1,42)=3.05, M S e=1577.16, p=.09$, ges $=.01, p \mathrm{H} 0=$ 0.59 . There was positive evidence against an overall effect of task difficulty on lexical decision accuracy, $F(2,84)=3.38, M S e=91.05, p=.04$, ges $=.03, p \mathrm{H} 0$ $=.76$ : The accuracies were $86 \%$ in the Difficult condition, $90 \%$ in the Moderate condition, and $91 \%$ in the Easy condition. Recognition hit rates showed very strong evidence for an effect of memory instruction, consistent with a directed forgetting effect, $F(1,42)=182.43, M S e=314.30, p<.01$, ges $=.48, p \mathrm{H} 1>.99 ;$ positive evidence against an effect of task difficulty, $F(2,84)$ $=2.56, \mathrm{MSe}=79.53, p=.08$, ges $=.01, p \mathrm{H} 0=.87$; and strong evidence against the critical interaction of memory instruction and task difficulty, $F(2,84)=1.09, M S e=94.78, p=.34$, ges $<.01, p \mathrm{H} 0=.97$. Under the Difficult, Moderate, and Easy conditions, respectively, the TBR item hit rate was $72 \%, 72 \%$, and $73 \%$, and the TBF item hit rate was $39 \%, 44 \%$, and $44 \%$.
}

relatively long, rather than a short, list of TBR items (Lee, 2012). These findings led Lee (2012) to propose the cognitive load hypothesis of item-method directed forgetting, suggesting that encoding information into long-term memory is enhanced by "any processing during study...that demands cognitive load" (p. 1112; Lee, 2012). According to Lee (2012), the mechanism for this effect is like the effects of perceptual load on distractor processing in attention tasks (Lavie, 2005, 2010): increasing perceptual load improves the ability to reallocate attentional resources to task-relevant items from taskirrelevant items. In a directed forgetting task, the relevant items are those designated TBR and the irrelevant items are those designated TBF. Thus, according to Lee's cognitive load hypothesis of directed forgetting, increasing cognitive load ironically improves directed forgetting by prompting changes in the allocation of attentional resources. The corollary is that there should be no such improvement when a difficult task prompts changes in attention due to data limitations. In contrast to the cognitive load hypothesis, we proposed an alternative task difficulty hypothesis which assumes that any changes to a task to make it more difficult, even perceptual changes, will be met with greater effort to perform the task, greater re-allocation of attentional resources away from TBF items, and better forgetting. To distinguish between the cognitive load hypothesis of directed forgetting and the task difficulty hypothesis, it was imperative that we manipulate task difficulty, not by limiting attentional resources (because the predictions of these hypotheses are identical under such conditions), but by limiting perceptual processes (i.e., creating data limitations). Across six experiments we manipulated study word data (sensory/perceptual) processing limitations in different ways.

In Experiments 1-3, we operationalised data limitations by introducing temporal constraints on the study words: study words were presented for $75 \mathrm{~ms}$ (Difficult), $300 \mathrm{~ms}$ (Moderate), or 1,200 ms (Easy). In the blocked design of Experiment 1, the evidence was against an interaction of memory instruction and study word duration. The same was true in the mixed design of Experiment 2. Importantly, when this same mixed design eliminated the need to intentionally forget and presented only TBR words (Experiment 3), there was also no evidence for an effect of study word duration on TBR hits. To the extent that recognition of TBR items studied alone operates similarly to recognition of TBR items studied in the context of TBF items (see Taylor et al., 2018), this suggests that a consistent failure to observe changes in directed forgetting due to study item processing duration was likely not attributable to coincident changes in TBR performance. In Experiment 4, we again varied word presentation time, while adding a lexical decision task prior to the study trials. The goal was to use the lexical decision task to corroborate that processing limitations vary inversely with word presentation time. Although errors increased with shorter word durations, 
this was offset by faster RTs, potentially the result of a strategy to prepare responding for (or to allocate more attentional resources to) the most difficult condition. Even so, there was evidence against an interaction of memory instruction with task difficulty.

In Experiment 5, words were displayed in light grey on a white background (Difficult), in mid-range grey (Moderate), or in black (Easy). A lexical decision task confirmed that the lowest contrast items (light grey) were more perceptually demanding than the higher contrast items (mid-range grey and black). In a similar vein, Experiment 6 presented study words in black, superimposed on isoluminant backgrounds of high (Difficult), moderate (Moderate), or no (Easy) visual noise. A lexical decision task successfully distinguished the three levels of perceptual processing, with the slowest RTs in the Difficult condition, intermediate RTs in the Moderate condition, and the fastest RTs in the Easy condition. Nevertheless, in both of these Experiments, the analysis of recognition hit rates provided evidence against an interaction of memory instruction with task difficulty.

Thus, across six experiments and three different manipulations of sensory/perceptual processing, there was no compelling evidence that data processing limitations improve directed forgetting in an item-method task. In this regard, the current work rules out the task difficulty hypothesis as a viable alternative to the cognitive load hypothesis of directed forgetting. Nevertheless, there are at least two conceptual challenges that face the cognitive load hypothesis when used to account for directed forgetting.

The first conceptual challenge to Lee's cognitive load theory comes from the fact that cognitive load appears to affect distractor processing differently in response competition tasks (i.e., increasing distractor processing) than it does in directed forgetting tasks (i.e., decreasing distractor processing). This is an uncomfortable theoretical wedge that will require future scrutiny. We posit three possible reasons for this discrepancy. First, it might have something to do with the inherent differences in the tasks used to measure attention versus memory, possibly related to differences in distractor suppression. In a response competition task, a distractor is something that ought to be suppressed at some stage of processing prior to a response. Distractor suppression therefore needs to operate quickly (e.g., within the first second of distractor presentation). In contrast, "distractor" processing in a directed forgetting task (i.e., a TBF item) is something that ought to be suppressed/avoided for much longer - at least for the duration of a TBF trial, but possibly much longer. Second, in response competition tasks, there is greater importance placed on spatial location. The location of a stimulus is a critical indicator of whether an item is designated as a distractor (and should be ignored) or as a target (and ought to be fully processed). In the directed forgetting paradigm, in contrast, all stimuli are typically presented at centre, so that location is not a useful feature for distinguishing "target" (TBR) from "distractor" (TBF) items. Third, in a response competition task the distractor and target are usually presented simultaneously. In contrast, how a study item is processed in the directed forgetting task depends entirely on the identity of the subsequent memory instruction. ${ }^{6}$ At this time, it is not clear whether any of these factors (or something else) is critical for resolving the discrepancy between the effects of cognitive load on distractor processing in a response competition task versus a directed forgetting task. However, this discrepancy is not trivial. And so long as it remains unaccounted for, there will be limited ability to relate the cognitive load hypothesis of directed forgetting to load theory more generally.

A second conceptual challenge for the cognitive load hypothesis of directed forgetting arises by considering the nature of the attentional changes that accompany dataprocessing limitations. Consider that the cognitive load hypothesis of directed forgetting specifies that unwanted TBF processing becomes less likely as attentional resources become unavailable under conditions of relatively high load, resulting in an increased directed forgetting effect. This would seem to suggest that the opposite could therefore also be true: under conditions in which attentional resources are brought to bear on TBF item processing, the magnitude of the directed forgetting effect should decrease. However, despite evidence that distractors are processed to a greater extent when visual stimuli are degraded (e.g., Lavie \& de Fockert, 2003; but see Benoni \& Tsal, 2010; Wilson et al., 2011), we did not find any evidence that manipulating the visual integrity of the study words affected efforts to remember and/or forget. In this regard, our findings were consistent with one tenet of the $\operatorname{cog}$ nitive load hypothesis of directed forgetting: that directed forgetting effects should increase only when attentional resources are taxed (and not when data limitations are imposed). Yet our findings are silent with respect to another tenet implied by Norman and Bobrow's (1975) seminal theoretical work: that greater restrictions on data processing may be offset by greater allocation of attentional resources and should lead to greater TBF item recognition and therefore to impaired directed forgetting. Of course, it is possible that Lavie and de Fockert's (2003) observations do not apply in this situation, and that there was, in fact, no increased allocation of attentional resources to study items under difficult sensory/ perceptual data processing conditions (e.g., see Yeshrun \& Marciano, 2013). Indeed, load theory, broadly considered, may be overly simple, suggesting that further work is needed to fully understand what it is about some tasks that seem capable of drawing from the attentional resources that cause

\footnotetext{
${ }^{6}$ This might be the most important difference between response competition and directed forgetting tasks. Perceptual load effects are only generally observed when there is an array of stimuli. It fits with dilution explanations of perceptual load such that dilution only occurs with a stimulus array. We thank Colin MacLeod, one of our reviewers, for highlighting this issue.
} 
us to remember when we need to forget (see Khetrapal, 2010; Cave \& Chen, 2016; Murphy et al., 2016, for discussion of other challenges to Lavie's load theory).

Regardless of the conceptual challenges that face the $c o g$ nitive load account of directed forgetting, one thing is clear: the mechanism(s) responsible for increased directed forgetting under conditions of attentional resource limitations (Lee \& Lee, 2011; Lee, 2012) are not obviously in play under conditions of data limitations. Across six experiments we obtained robust directed forgetting effects, with no evidence that the magnitude of these effects was influenced by data limitations to study item processing. Our results demonstrate that a memory intention is sufficient to produce intentional remembering and forgetting when there is no other competition for limitedcapacity attentional resources. By implication, our results also suggest that if high loads lead to improved forgetting - as postulated by the cognitive load hypothesis of directed forgetting - they do so through direct competition for attentional resources, and not through changes in attention prompted by perceptual challenges.

Author Note Authorship order is arbitrary; equal contributions were made by both authors. Thanks to Dr. Jonathan Fawcett for providing the custom software used to randomise and distribute the word stimuli to different lists; Laura Cutmore and Colin McCormick for collecting data; Dr. Charles Collin for providing code to create the visual noise images used in Experiment 6; to students Noha Mohamed and Jessie Pappin for collecting data in earlier versions of Experiment 6; and, to participants for volunteering their time and effort to contribute data toward this project. Project funding was provided by an NSERC Discovery Grant awarded to TLT.

\section{References}

Ahmad, F. N., Tan, P., \& Hockley, W. E. (2019). Directed forgetting for categorized pictures: Recognition memory for perceptual details versus gist. Memory, 27(7), 894-903. https://doi.org/10.1080/ 09658211.2019 .1591456

Anderson, M. C., \& Hanslmayr, S. (2014). Neural mechanisms of motivated forgetting. Trends in Cognitive Sciences, 18(6), 279-292. https://doi.org/10.1016/j.tics.2014.03.002

Aron, A. R., Fletcher, P. C., Bullmore, E. T., Sahakian, B. J., \& Robbins, T. W. (2003). Stop-signal inhibition disrupted by damage to right inferior frontal gyrus in humans. Nature Neuroscience, 6(2), 115116. https://doi.org/10.1038/nn1003

Aron, A. R., \& Poldrack, R. A. (2006). Cortical and subcortical contributions to stop signal response inhibition: Role of the subthalamic nucleus. The Journal of Neuroscience, 26(9), 2424-2433. https:// doi.org/10.1523/JNEUROSCI.4682-05.2006

Aron, A. R., Robbins, T. W., \& Poldrack, R. A. (2004). Inhibition and the right inferior frontal cortex. Trends in Cognitive Sciences, 8(4), 170 177. https://doi.org/10.1016/j.tics.2004.02.010

Bancroft, T. D., Hockley, W. E., \& Farquhar, R. (2013). The longer we have to forget the more we remember: The ironic effect of postcue duration in item-based directed forgetting. Journal of Experimental Psychology: Learning, Memory, and Cognition, 39(3), 691-699. https://doi.org/10.1037/a0029523
Basden, B. H., \& Basden, D. R. (1996). Directed forgetting: Further comparison of item and list methods. Memory, 4(6), 633-654. https://doi.org/10.1080/741941000

Bastin, C., Feyers, D., Majerus, S., Balteau, E., Degueldre, C., Luxen, A., Maquet, P., Salmon, E., \& Collette, F. (2012). The neural substrates of memory suppression: a FMRI exploration of directed forgetting. PloS one, 7(1), e29905. https://doi.org/10.1371/journal.pone. 0029905

Benoni, H. (2018). Can automaticity be verified utilizing a perceptual load manipulation? Psychonomic Bulletin \& Review, 25(6), 2037 2046. https://doi.org/10.3758/s13423-018-1444-7

Benoni, H., \& Tsal, Y. (2010). Where have we gone wrong? Perceptual load does not affect selective attention. Vision Research, 50, 1292 1298. https://doi.org/10.1016/j.visres.2010.04.018

Cave, K. R., \& Chen, Z. (2016). Identifying visual targets amongst interfering distractors: Sorting out the roles of perceptual load, dilution, and attentional zoom. Attention, Perception, \& Psychophysics, 78(7), 1822-1838. https://doi.org/10.3758/s13414-016-1149-9

Cheng, S., Liu, I., Lee, J. R., Hung D. L., \& Tzeng, O. J-L. (2012). Intentional forgetting might be more effortful than remembering: An ERP study of item-method directed forgetting. Biological Psychology, 89, 283-292. https://doi.org/10.1016/j.biopsycho. 2011.10.019

Cohen, J. D., MacWhinney, B., Flatt, M., \& Provost, J. (1993). PsyScope: An interactive graphic system for designing and controlling experiments in the psychology laboratory using Macintosh computers. Behavior Research Methods, Instruments, \& Computers, 25, 257-271. https:// doi.org/10.3758/BF03204507

Coltheart, M. (1981). The MRC Psycholinguistic database. Quarterly Journal of Experimental Psychology, 33A, 497-505. https://doi. org/10.1080/14640748108400805

Davis, J. C., \& Okada, R. (1971). Recognition and recall of positively forgotten items. Journal of Experimental Psychology, 89(1), 181186. https://doi.org/10.1037/h0031183

Fawcett, J. M., Lawrence, M. A., \& Taylor, T. L. (2016). The representational consequences of intentional forgetting: Impairments to both the probability and fidelity of long-term memory. Journal of Experimental Psychology: General, 145 (1), 56-81. https://doi. org/10.1037/xge0000128

Fawcett, J. M., \& Taylor, T. L. (2008). Forgetting is effortful: Evidence from reaction time probes in an item-method directed forgetting task. Memory \& Cognition, 6, 1168-1181. https://doi.org/10.3758/ MC.36.6.1168

Fawcett, J. M., \& Taylor, T. L. (2010). Directed forgetting shares mechanisms with attentional withdrawal but not with stop-signal inhibition. Memory \& Cognition, 38(6), 797-808. https://doi.org/10.3758/ MC.38.6.797

Fawcett, J. M., \& Taylor, T. L. (2012). The control of working memory resources in intentional forgetting: Evidence from incidental probe word recognition. Acta Psychologica, 139, 84-90. https://doi.org/ 10.1016/j.actpsy.2011.10.001

Fawcett, J. M., Taylor, T. L., \& Nadel, L. (2013a). Event-method directed forgetting: Forgetting a video segment is more effortful than remembering it. Acta Psychologica, 144, 332-343. https://doi.org/10.1016/ j.actpsy.2013.07.005

Fawcett, J. M., Taylor, T. L., \& Nadel, L. (2013b). Intentional forgetting diminishes memory for continuous events. Memory, 21(6), 675694. https://doi.org/10.1080/09658211.2012.748078

Gao, H., Cao, B., Zhang, Q., Qi, M., Li, F., \& Li, H. (2016). Intending to forget is not easy: Behavioral and electrophysiological evidence. International Journal of Psychophysiology, 104, 1-9. https://doi. org/10.1016/j.ijpsycho.2016.03.007

Gao, H., Qi, M., \& Zhang, Q. (2019). Forgetting cues are ineffective in promoting forgetting in the item-method directed forgetting paradigm. International Journal of Psychophysiology, 144, 25-33. https://doi.org/10.1016/j.jpsycho.2019.07.004 
Gardiner, J. M., Gawlik, B., \& Richardson-Klavehn, A. (1994). Maintenance rehearsal affects knowing, not remembering; elaborative rehearsal affects remembering, not knowing. Psychonomic Bulletin \& Review, 1(1), 107-110. https://doi.org/10.3758/ BF03200764

Gaspelin, N., Ruthruff, E., \& Jung, K. (2014). Slippage theory and the flanker paradigm: An early-selection account of selective attention failures. Journal of Experimental Psychology: Human Perception and Performance, 40(3), 1257-1273. https://doi.org/10.1037/ a0036179

Hauk, O., Davis, M. H., Ford, M., Pulvermüller, F., \& Marslen-Wilson, W. D. (2006). The time course of visual word recognition as revealed by linear regression analysis of ERP data. Neuroimage, 30(4), 1383-1400. https://doi.org/10.1016/j.neuroimage.2005.11. 048

Hockley, W. E., Ahmad, F. H., \& Nicholson, R. (2016). Intentional and incidental encoding of item and associative information in the directed forgetting procedure. Memory \& Cognition, 44, 220-228. https://doi.org/10.3758/s13421-015-0557-8

Hourihan, K. L., \& Taylor, T. L. (2006). Cease remembering: Executive control processes in directed forgetting. Journal of Experimental Psychology: Human Perception \& Performance, 32, 1354-1365. https://psycnet.apa.org/doi/10.1037/0096-1523.32.6.1354

Hsieh, L. T., Hung, D. L., Tzeng, O. J. L., Lee, J. R., \& Cheng, S. K. (2009). An event-related potential investigation of the processing of Remember/Forget cues and item encoding in item-method directed forgetting. Brain Research, 1250, 190-201. https://doi.org/10.1016/ j.brainres.2008.11.016

Jing, J., Qi, M., Gao, H., \& Zhang, Q. (2019). The role of forgetting cues in directed forgetting: Ceasing maintenance rehearsal. Acta Psychologica, 199, 102922. https://doi.org/10.1016/j.actpsy.2019. 102922

Khetrapal, N. (2010). Load theory of selective attention and the role of perceptual load: Is it time for revision? European Journal of Cognitive Psychology, 22(1), 149-156. https://doi.org/10.1016/j. actpsy.2019.102922

Kruschke, J. K., \& Liddell, T. M. (2017). The Bayesian New Statistics: Hypothesis testing, estimation, meta-analysis, and power analysis from a Bayesian perspective. Psychonomic Bulletin \& Review, 129. https://doi.org/10.3758/s13423-016-1221-4

Lavie, N. (2005). Distracted and confused?: Selective attention under load. Trends in Cognitive Sciences, 9(2), 75-82. https://doi.org/10. 1016/j.tics.2004.12.004

Lavie, N. (2010). Attention, distraction, and cognitive control under load. Current Directions in Psychological Science, 19(3), 143-148. https://doi.org/10.1177/0963721410370295

Lavie, N., \& de Fockert, J. W. (2003). Contrasting effects of sensory limits and capacity limits in visual selective attention. Perception \& Psychophysics, 65(2), 202-212. https://doi.org/10.3758/ BF03194795

Lavie, N., Hirst, A., de Fockert, J.W., \& Viding, E. (2004). Load theory of selective attention and cognitive control. Journal of Experimental Psychology: General, 133, 339-354

Lawrence, M. A. (2016). ez: Easy Analysis and Visualization of Factorial Experiment. Package version 4.4-0. https://CRAN.R-pro9ject.org/ package $=\mathrm{ez}$

Lee, Y. S. (2012). Cognitive load hypothesis of item-method directed forgetting. The Quarterly Journal of Experimental Psychology, 65(6), 1110-1122. https://doi.org/10.1080/17470218.2011.644303

Lee, Y. S. (2013). Costs and benefits in item-method directed forgetting: Differential effects of encoding and retrieval. The Journal of General Psychology, 140(3), 159-173. https://doi.org/10.1080/ 00221309.2012 .750591

Lee, Y. S. (2018). Withdrawal of spatial overt attention following intentional forgetting: Evidence from eye movements. Memory, 26(4), 503-513. https://doi.org/10.1080/09658211.2017.1378360
Lee, Y. S., \& Hsu, Y. (2012). How do we forget negative events? The role of attentional, cognitive, and metacognitive control. Cognition \& Emotion, 27(3), 1-15. https://doi.org/10.1080/02699931.2012. 713326

Lee, Y. S., \& Lee, H. M. (2011). Divided attention facilitates intentional forgetting: Evidence from item-method directed forgetting. Consciousness \& Cognition, 20(3), 618-626. https://doi.org/10. 1016/j.concog.2010.09.008

Lee, Y., Lee, H., \& Tsai, S. (2007). Effects of post-cue interval on intentional forgetting. British Journal of Psychology, 98(2), 257-272. https://doi.org/10.1348/000712606X120410

MacLeod, C. M. (1998). Directed forgetting. In J. M. Golding \& C. M. MacLeod (Eds.), Intentional Forgetting: Interdisciplinary Approaches (pp. 1-57). Mahwah, NJ: Lawrence Erlbaum Associates, Inc.

Marevic, I., \& Rummel, J. (2020). Retrieval-mediated directed forgetting in the item-method paradigm: The effect of semantic cues. Psychological research, 84(3), 685-705. https://doi.org/10.1007/ s00426-018-1085-5

Masson, M. E. (2011). A tutorial on a practical Bayesian alternative to null-hypothesis significance testing. Behavior Research Methods, 43(3), 679-690. https://doi.org/10.3758/s13428-010-0049-5

Montagliani, A., \& Hockley, W. E. (2019). Item-based directed forgetting for categorized lists: Forgetting of words that were not presented. Canadian Journal of Experimental Psychology, 73(3). 135-143. https://psycnet.apa.org/doi/10.1037/cep0000177

Murphy, G., Groeger, J. A., \& Greene, C. M. (2016). Twenty years of load theory - Where are we now, and where should we go next? Psychonomic Bulletin \& Review, 23(5), 1316-1340. https://doi.org/ 10.3758/s13423-015-0982-5

Norman, D. A., \& Bobrow, D. G. (1975). On data-limited and resourcelimited processes. Cognitive Psychology, 7, 44-64. https://doi.org/ 10.1016/0010-0285(75)90004-3

Paller, K. A. (1990). Recall and stem-completion priming have different electrophysiological correlates and are modified differentially by directed forgetting. Journal of Experimental Psychology: Learning, Memory, and Cognition, 16, 1021-1032. https:// psycnet.apa.org/doi/10.1037/0278-7393.16.6.1021

Paz-Caballero, M. D., Menor, J., \& Jiménez, J. M. (2004). Predictive validity of event-related potentials (ERPs) in relation to the directed forgetting effects. Clinical Neurophysiology, 115(2), 369-377. https://doi.org/10.1016/j.clinph.2003.09.011

Popov, V., Marevic, I., Rummel, J., \& Reder, L. M. (2019). Forgetting is a feature, not a bug: Intentionally forgetting some things helps us remember others by freeing up working memory resources. Psychological Science, 30(9), 1303-1317. https://doi.org/10.1177/ 0956797619859531

Quinlan, C. K., Taylor, T. L., \& Fawcett, J. M. (2010). Directed forgetting: Comparing pictures and words. Canadian Journal of Experimental Psychology, 64(1), 41-46. https://doi.org/10.1037/ a0016569

R Core Team (2019). R: A language and environment for statistical computing. R Foundation for Statistical Computing, Vienna, Austria. URL http://www.R-project.org/.

Raftery, A. E. (1995). Bayesian model selection in social research. Sociological Methodology, 25, 111-164.

Rizio, A. A., \& Dennis, N. A. (2013). The neural correlates of cognitive control: Successful remembering and intentional forgetting. Journal of Cognitive Neuroscience, 25, 297-312. https://doi.org/10.1162/ jocn_a_00310

Rubinfeld, L. M., Taylor, T. L., \& Hamm, J. P. (2019). Selection for encoding: No evidence of better endogenous orienting following forget than following remember instructions. Attention, Perception, \& Psychophysics, 81, 237-252. https://doi.org/10. 3758/s13414-018-1587-7 
Sahakyan, L., \& Foster, N. L. (2009). Intentional forgetting of actions: Comparison of list-method and item-method directed forgetting. Journal of Memory and Language, 61(1), 134-152. https://doi.org/ 10.1016/j.jml.2009.02.006

Scholz, S., \& Dutke, S. (2019). Investigating intentional forgetting using pupillometry: No evidence for the ongoing allocation of cognitive resources during forgetting. Journal of Cognitive Psychology, 31(4), 416-437. https://doi.org/10.1080/20445911.2019.1622548

Tan, P., Ensor, T. M., Hockley, W. E., Harrison, G. W., \& Wilson, D. E. (2020). In support of selective rehearsal: Double-item presentation in item-method directed forgetting. Psychonomic Bulletin \& Review, 27, 529-535. https://doi.org/10.3758/s13423-020-01723-w

Taylor, T. L. (2005). Inhibition of return following instructions to remember and forget. The Quarterly Journal of Experimental Psychology, $58 \mathrm{~A}, 613$ - 629 (Erratum in 58A, 1343). 10.1080/ 02724980443000115

Taylor, T. L. (2018). Remember to blink: Reduced attentional blink following instructions to forget. Attention, Perception, \& Psychophysics, 80(6), 1489-1503. https://doi.org/10.3758/s13414018-1528-5

Taylor, T. L., \& Hamm, J. P. (2016). Selection for encoding: No evidence of greater attentional capture following forget than remember instructions. Attention, Perception, \& Performance, 78, 168-186. https://doi.org/10.3758/s13414-015-0984-4

Taylor, T. L., \& Hamm, J. P. (In Press). Intention matters more than attention: Item-method directed forgetting of items at attended and unattended locations. Attention, Perception, and Pychophysics.

Taylor, T. L., \& Fawcett, J. M. (2011). Larger IOR effects following forget than following remember instructions depend on exogenous attentional withdrawal and target localization. Attention, Perception, \& Psychophysics, 73, 1790-1814. https://doi.org/10.3758/s13414011-0146-2

Thompson, K. M., \& Taylor, T. L. (2015). Memory instruction interacts with both visual and motoric inhibition of return. Attention, Perception, \& Psychophysics, 77(3), 804-818. https://doi.org/10. 3758/s13414-014-0820-2

Thompson, K. M., Fawcett, J. M., \& Taylor, T. L. (2011). Tag you're it: Tagging as an alternative to yes/no recognition in item method directed forgetting. Acta Psychologica, 138(1), 171-175. https://doi. org/10.1016/j.actpsy.2011.06.001

Thompson, K. M., Hamm, J. P., \& Taylor, T. L. (2014). Effects of memory instruction on attention and information processing: Further investigation of inhibition of return in item-method directed forgetting. Attention, Perception, \& Psychophysics, 76, 322-334. https:// doi.org/10.3758/s13414-013-0584-0

Taylor, T. L., Quinlan, C. K., \& Vullings, K. C. (2018). Decomposing item-method directed forgetting of emotional pictures: Equivalent costs and no benefits. Memory \& Cognition, 46(1), 132-147. https:// doi.org/10.3758/s13421-017-0751-y

Tsal, Y., \& Benoni, H. (2010). Diluting the burden of load: Perceptual load effects are simply dilution effects. Journal of Experimental Psychology: Human Perception and Performance, 36, 1645-1656. https://doi.org/10.1037/a0018172 van Hooff, J. C., \& Ford, R. M. (2011). Remember to forget: ERP evidence for inhibition in an item-method directed forgetting paradigm. Brain Research, 1392, 80-92. https://doi.org/10.1016/j.brainres. 2011.04.004

Wang, T. H., Placek, K., \& Lewis-Peacock, J. A. (2019). More is less: Increased processing of unwanted memories facilitates forgetting. Journal of Neuroscience, 39(18), 3551-3560. https://doi.org/10. 1523/JNEUROSCI.2033-18.2019

Wegner, D. M. (1994). Ironic processes of mental control. Psychological Review, 101(1), 34-52. https://psycnet.apa.org/doi/10.1037/0033295X.101.1.34

Wickham, H. (2009). ggplot2: elegant graphics for data analysis. Springer New York. http:/had.co.nz/ggplot2/book

Wickham, H. (2011). plyr: The split-apply-combine strategy for data analysis. Journal of Statistical Software, 40, 1-29. http://www. jstatsoft.org/v40/i01/.

Wickham, H., \& Henry, L. (2019). tidyr: Tidy Messy Data. R package version 1.0.0. https://CRAN.R-project.org/package=tidyr

Wickham, H. (2019). stringr: Simple, Consistent Wrappers for Common String Operations. Package version 1.4.0. https://CRAN.R-project. org/package $=$ stringr

Wickham, H. \& Francois, R. (2019). dplyr: A grammar of data manipulation. R package version 0.8.3. https://CRAN.R-project. org $/$ package $=$ dplyr

Wilson, M. D. (1988). The MRC Psycholinguistic database: Machine readable dictionary, version 2. Behavioural Research Methods, 20(1), 6-11. https://doi.org/10.3758/BF03202594

Wilson, D. E., Muroi, M., \& MacLeod, C. M. (2011). Dilution, not load, affects distractor processing. Journal of Experimental Psychology: Human Perception \& Performance, 37, 319-335. https://doi.org/10. 1037/a0021433

Woodward Jr, A. E., Bjork, R. A., \& Jongeward Jr, R. H. (1973). Recall and recognition as a function of primary rehearsal. Journal of Verbal Learning and Verbal Behavior, 12(6), 608-617. https://doi.org/10. 1016/S0022-5371(73)80040-4

Wylie, G. R., Foxe, J. J., \& Taylor, T. L. (2008). Forgetting as an active process: An fMRI investigation of item-method directed forgetting. Cerebral Cortex, 18, 670-682. https://doi.org/10.1093/cercor/ bhm101

Xie, H., Chen, Y., Lin, Y., Hu, X., \& Zhang, D. (2020). Can't forget: disruption of the right prefrontal cortex impairs voluntary forgetting in a recognition test. Memory, 28(1), 60-69. https://doi.org/10.1080/ 09658211.2019 .1681456

Yeshrun, Y., \& Marciano, H. (2013). Degraded stimulus visibility and the effects of perceptual load on distractor interference. Frontiers in Psychology, 4, 289. https://doi.org/10.3389/fpsyg.2013.00289

Zwissler, B., Schindler, S., Fischer, H., Plewnia, C., \& Kissler, J. M. (2015). 'Forget me (not)?'-remembering forget-items versus uncued items in directed forgetting. Frontiers in Psychology, 6, 1741. https://doi.org/10.3389/fpsyg.2015.01741

Publisher's Note Springer Nature remains neutral with regard to jurisdictional claims in published maps and institutional affiliations. 